\title{
SIGNIFICANCE OF VENOUS GRAFT DIAMETER AND LENGTH FOR PERIPHERAL BY-PASS PATENCY
}

\author{
Mihail V. Cheshmedzhiev, Emil D. Jordanov, Miroslav D. Yordanov. \\ Department of Vascular Surgery, St. Marina University Hospital, Varna, Bulgaria.
}

\begin{abstract}
:
Objective: To analyze the one-year-patency of infrainguinal arterial reconstructions in relation to venous graft diameter and length .

Material and Methods: 56 patent and failed infrainguinal autovenous by-pass reconstructions were followed up for no less than a year. The diameter of the vein was measured at the site of distal anastomosis, and the length after the completion of reconstruction.

Results: Results are worse in venous grafts with diameter less than $3.5 \mathrm{~mm}$ and length over $40 \mathrm{~cm}$, but the difference between failed and patent by-passes with diameter over $3.5 \mathrm{~mm}$ and bigger length is also significant. Shorter and with diameter over $3.5 \mathrm{~mm}$ by-passes have the higher percentage patency.
\end{abstract}

Conclusion: Shorter grafts with diameter above $3.5 \mathrm{~mm}$ do not guarantee longer patency if distal anastomosis is constructed above diseased run-off segment.

Key words: diameter, length, venous by-pass.

\section{INTRODUCTION}

Reconstruction surgery of the vessels of the lower extremities develops in relation to the high incidence of peripheral arterial disease (PAD). Risk factors as hypertension, hyperlypidemy, diabetes mellitus and smoking are seen more frequently.

One third of arterial occlusions occur in the aorto-iliac segment and two thirds in the arteries below inguinal ligament.

Despite improvement of revascularization techniques, 5 to $10 \%$ of by-passes fail up to 30 days after reconstruction $^{(1)}$. Walsh D.B. and al. ${ }^{(2)}$ discover that technical mistakes cause $25 \%$ of early thromboses. Patency of each reconstruction depends on combination of 3 different factors - surgical, haemodynamical and biological.

Surgical factor includes the surgical technique (continuous or interrupted sewing technique, graft material - vein, artery of synthetic material), geometry of anastomosis (form and size) and last but not least skill and experience of surgeon.

Haemodynamical factor includes anastomotic inflow, run-off, characteristics of flow (turbulent flow with stagnation, separation and recirculation) and degree of stenosis. Haemodynamic success concerns the whole extremity and therefore distal sites of observation are used.

Size of graft and its quality are also major determinants of long term success of infrainguinal reconstructions. Exact measurement of internal venous diameter is difficult due to different wall thickness and conical narrowing ${ }^{(3)}$. Wengerter and al. ${ }^{(4)}$ demonstrate model of increasing patency in venous grafts ranging from $3.0 \mathrm{~mm}$ to $4.0 \mathrm{~mm}$, and Idu and al. ${ }^{(5)}$ consider only venous graft diameter below $3.5 \mathrm{~mm}$ important for development of stenoses.

Operative technique, namely reversed against nonreversed configurations, received significant attention lately, but there is no solid evidence for extended patency of any of the techniques ${ }^{(6)}$.

\section{MATHERIALS AND METHODS}

56 infrainguinal autovenous by-passes were followed -24 patent (not less than 1 year) and 32 failed by-passes (12 with stenoses of distal anastomosis and 20 with thrombosis of grafts). Translocated VSM was used in 46 reconstructions, in situ venous graft in 2 and reversed vein in 4 . Small saphenous vein was used in 4 by-passes. Diameter of vein was measured at the distal anastomosis and the length after the completion of the by-pass. Long were considered bypasses with length over $40 \mathrm{~cm}$ (LVGs) - 26 of all and below $40 \mathrm{~cm}$ were considered short (SVGs) -30 of all. 22 have diameter less than $3.5 \mathrm{~mm}$ and 34 - over $3.5 \mathrm{~mm}$.

In the postoperative period patients were followed by clinical examination, Ankle Brachial Index (ABI) measurement and duplex ultra sound every month up to 1 year after operation.

Criteria for high grade stenosis is accepted to be reduction of $\mathrm{ABI}$ and difference in velocities in two adjacent segments of inflow arteries, outflow arteries or the graft (V1/ V2) over 2.5. These criteria were accepted as indication for control angiography.

\section{RESULTS}

Thrombosed venous grafts with diameter less than 3.5 $\mathrm{mm}$ are $46 \%$ and with diameter over $3.5 \mathrm{~mm}$ are $30 \%$ (fig. 1a). 
Venous grafts with stenoses of distal anstomosis and diameter less than $3.5 \mathrm{~mm}$ are $15 \%$, with diameter over $3.5 \mathrm{~mm}$ are $23 \%$. Patent by-passes are respectively 39\% (more than a half anastomosed to tibial arteries with small diameter) and $47 \%$ (with diameter over $3.5 \mathrm{~mm}$ ). Length of graft over $40 \mathrm{~cm}$ is related to thromboses in $48 \%$, stenoses in $15 \%$ (total of $63 \%$ ), while complications at length less than $40 \mathrm{~cm}$ are respectively $28 \%$ and $24 \%$ (total of $52 \%$ ) - high percentage of failed reconstructions with smaller length.

Results are worse in venous grafts with diameter less than $3.5 \mathrm{~mm}$ and length over $40 \mathrm{~cm}$ (fig. 1b) but the difference between failed and patent by-passes with diameter over 3.5 $\mathrm{mm}$ and bigger length is also significant $-28 \%$. Shorter and with diameter over $3.5 \mathrm{~mm}$ by-passes have the higher percentage patency.

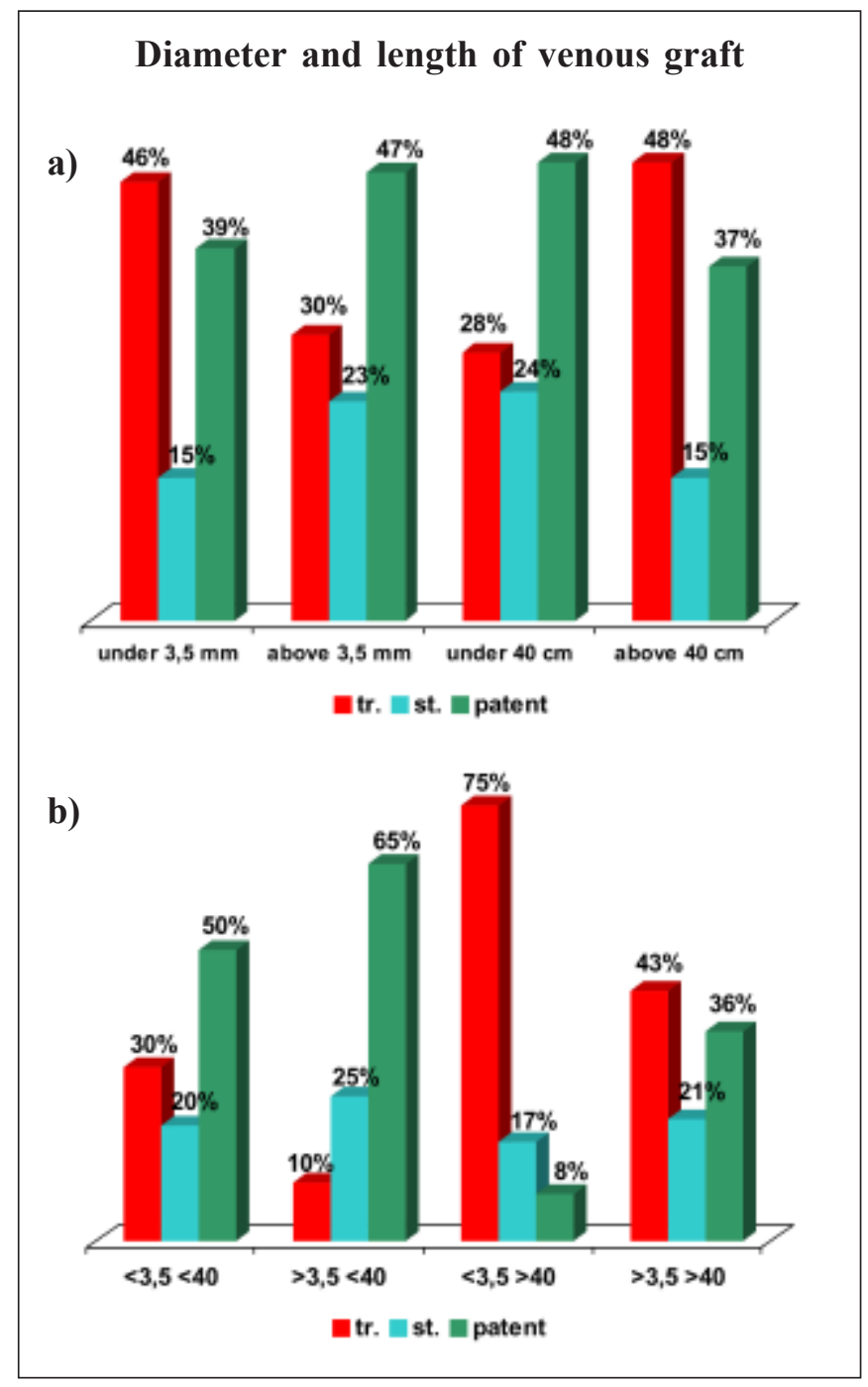

Fig. 1 a \& b. Comparison of failed and patent reconstructions with autovenous graft in terms of a) diameter and length of vein and $b$ ) their combination.

\section{DISCUSSION}

Tangelder M. and al. emphasized in their study ${ }^{(7)}$ the significance of 3 main factors for the thrombosis of infrainguinal reconstructions: length of by-pass, arterial runoff and material and diameter of the graft. Smaller length suggests more preserved venous segment with optimal distal diameter.

In our study this dependency was not fully confirmed - high percent failed reconstructions with diameter over 3.5 $\mathrm{mm}-53 \%$ of venous grafts with stenoses and thromboses against $61 \%$ of by-passes with diameter under $3.5 \mathrm{~mm}$.

Necessity of longer grafts is due to multi segmental spread of the disease ${ }^{(8)}$, including partial involvement of run-off arteries, that is why failed by-passes, independently on their greater diameter (over $3.5 \mathrm{~mm}$ ), but for bigger length prevail over patent ones by $28 \%$.

Some studies have shown that poor run-off affects negatively the patency of infrainguinal reconstructions ${ }^{(9-}$ 11). Patency of infrainguinal by-pass and subsequent limb salvage depend crucially on the quality of the distal arterial segment.

Haemodynamic assessment of recipient arteries below the level of distal anastomosis is necessary ${ }^{(12)}$. Used assays include measurement of mean blood flow, wave shape, velocity of flow, resistance and impedance.

\section{CONCLUSION}

Venous graft failing is due to technical mistake during harvesting of vein and anstomoses construction, lack of congruence of vein and artery diameters, poor run-off segment with low out-flow and subsequent thrombosis or stenosis. Quality of the run-off arterial segment is of crucial significance either in target artery selection, or in postoperative period in order of spread and advance of the disease. Use of short venous grafts is limited in wide spread of the occlusive disease and good quality of longer venous segment is uncertain. 


\section{REFERENCES:}

1. Budd JS, Brennan J, Beard JD, Warren H, Burton PR, Bell PR. Warren infrainguinal bypass surgery: factors determining late graft patency. $B r . J$. Surg. 1990 Dec;77(12):1382-1387. [PubMed]

2. Walsh DB, Zwolak RM, McDaniel MD, Schneider JR, Cronenwett JL. Intragraft drug infusion as an adjunct to balloon catheter thrombectomy for salvage of thrombosed infragenicular vein grafts: A preliminary report. J Vasc Surg. 1990 Jun;11(6):753-759. [PubMed]

3. Meyerson SL, Moawad J, Loth F, Skelly CL, Bassiouny HS, McKinsey JF, et al. Effective hemodynamic diameter: An intrinsic property of vein grafts with predictive value for patency. $J$ Vasc Surg. 2000 May;31(5):910-7. [PubMed] [CrossRef]

4. Wengerter KR, Veith FJ, Gupta SK, Ascer E, Rivers SP. Influence of vein size (diameter) on infrapopliteal reversed vein graft patency. $J$ Vasc Surg. 1990 Apr;11(4):525-31. [PubMed]
5. Idu MM, Buth J, Hop WC, Cuypers $\mathrm{P}$, van de Pavoordt ED, Tordoir JM. Factors influencing the development of vein-graft stenosis and their significance forclinical management. Eur J Vasc Endovasc Surg. 1999 Jan;17(1): 15-21. [PubMed] [CrossRef]

6. Gupta AK, Bandyk DF, Cheanvechai D, Johnson BL. Natural history of infrainguinal vein graft stenosis relative to bypassgrafting technique. J Vasc Surg. 1997 Feb; 25(2): 211-25. [PubMed]

7. Tangelder MJ, Algra A, Lawson JA, Eikelboom BC. Risk factors for occlusion of infrainguinal bypass grafts. Eur J Vasc Endovasc Surg. 2000 Aug;20(2):118-124. [PubMed] [CrossRef]

8. Slim H, Tiwari A, Ahmed A, Ritter JC, Zayed H, Rashid H. Distal versus Ultradistal Bypass Grafts: Amputation free survival and patency rates in patients with critical leg ischaemia. Eur J Vasc Endovasc Surg. 2011 Jul;42(1):
83-88. [Pubmed] [CrossRef]

9. Donaldson MC, Mannick JA, Whittemore AD. Causes of primary graft failure after in situ saphenous vein bypass grafting J Vasc Surg. 1992 Jan;15(1):113-118. [PubMed]

10. Harrington EB, Harrington ME, Schanzer H, Jacobson JH, Haimov M. The dorsalis pedis bypass - moderate success in difficult situations. $J$ Vasc Surg. 1992 Feb;15(2):409-414. [PubMed]

11. Schweiger H, Klein P, Lang W. Tibial bypass grafting for limb salvage with ringed polytetrafluoroethylene prostheses: results of primary and secondary procedures. J Vasc Surg. 1993 Nov;18(5):867-874. [PubMed]

12. Hobbs SD, Pinkney T, Sykes TC, Fox AD, Houghton AD. Patency of infra-inguinal vein grafts - effect of Intraoperative Doppler assessment and a graft surveillance program. $J$ Vasc Surg. 2009 Jun;49(6):1452-1458. [PubMed] [CrossRef]

Address for correspondence:

Dr. Mihail Cheshmedzhiev, Department of Vascular Surgery

St. Marina University Hospital, Varna, Bulgaria E-mail: mi6046@gmail.com; 